\section{A high grade pleural based sarcoma in a patient with rheumatoid arthritis and a 7-year history of anti-tumour necrosis factor alpha therapy}

Martin A. Lee,' Rahul Bhatnagar, Martin Davis, ${ }^{3}$ Dinesh Shrikrishna ${ }^{4}$

${ }^{1}$ Rheumatology Department, National

Hospital of Rheumatic Diseases, Bath; ${ }^{2}$ Respiratory Department, Royal Devon \& Exeter Hospital, Exeter; ${ }^{3}$ heumatology Department and ${ }^{4}$ Respiratory Department, Royal Cornwall Hospital, Truro, UK

\section{Abstract}

The use of anti-tumour necrosis factor alpha (anti-TNF $\alpha$ ) therapies has increased over the past few years. Concerns have been raised about the theoretical increased risk of malignancy in patients receiving these therapies. We report a case of an extremely rare high grade pleural based sarcoma in a patient with rheumatoid arthritis and a 7-year history of anti-TNF $\alpha$ therapy.

\section{Case Report}

A 70-year old female presented with 4 weeks of dry cough and mild dyspnoea. There was also reduced appetite and significant weight loss over the preceding months. She had never smoked. Fourteen years previously, she had been diagnosed with Rheumatoid Arthritis (RA) and had been managed with a variety of agents including sulphasalazine, intramuscular gold, methotrexate, hydroxychloroquine, leflunomide and prednisolone. In 2000 she commenced anti-TNF $\alpha$ therapy (etanercept $25 \mathrm{mg}$ subcutaneous twice weekly) due to continuing poor control of disease. This was augmented at various times with intramuscular gold, prednisolone and a brief trial of azathioprine. Despite this, her disease progressed and she developed cutaneous vasculitis requiring intravenous methylprednisolone. At presentation, she had a 7-year history of anti-TNFa treatment.

A chest radiograph was performed which revealed a large, right-sided upper zone mass (Figure 1). Blood tests revealed a mild normochromic, normocytic anaemia, with raised inflammatory markers (CRP of $182 \mathrm{mg} / \mathrm{L}$ and an ESR of 103.) Her etanercept was stopped and an urgent staging CT thorax was performed.

The CT revealed a large right-sided intrathoracic mass arising from the chest wall, with no evidence of metastasis. There was no lymphadenopathy and the lung parenchyma appeared normal. Subsequent core biopsy revealed a cellular spindle cell tumour. At thoracotomy a large, multinodular, capsulated, pleural-based tumour was successfully removed. Histology showed a high-grade solitary fibrous sarcoma.

\section{Conclusions}

High-grade pleural based sarcomas are extremely rare tumours and only a small number of cases have been reported. Anti-TNF $\alpha$ therapies are relatively novel chemotherapeutic agents and their long-term effects are still unknown.

In vivo, TNF- $\alpha$ is thought to have a protective effect against cancer development but the mechanism by which this occurs, and therefore how its inhibition may promote cancer, is not fully understood. TNF- $\alpha$ promotes killing of tumour cells through apoptosis, by stimulating natural killer cells and by inducing CD-8 killer cells. ${ }^{1-2}$ In vitro, TNF- $\alpha$ has demonstrated potent anti-tumour activity in a number of carcinomatous cell lines. Given this, it is theoretically plausible that loss of TNF- $\alpha$ activity could predispose to unregulated cellular proliferation and hence carcinogenesis. However, a new paradigm is becoming widely accepted that chronic inflammation, driven in part by chemokines and cytokines at the site of a tumour, may facilitate tumour progression instead of promoting anti-tumour immunity. ${ }^{2-3}$ Recent advances in cancer biology have demonstrated than TNF- $\alpha$ can act paradoxically as both an anti-tumour agent as well as a promoter of tumour growth, and that pathophysiological concentrations of endogenous TNF- $\alpha$ can enhance tumour genesis and growth. ${ }^{4}$ Anti-TNF- $\alpha$ therapies have been trialled with limited success in the treatment of a number of haematological malignancies such as multiple myeloma and myelodysplastic syndrome. ${ }^{4}$ In 2008, Egberts at al. examined the role of TNF- $\alpha$ in pancreatic tumour activity. ${ }^{5}$ They demonstrated that TNF- $\alpha$ strongly increased the invasiveness of pancreatic ductal adenocarcinoma cells in vitro, and that in vivo inhibition of TNF- $\alpha$ exerted strong antitumour effects on mouse-models. The study concluded that TNF- $\alpha$ inhibition may represent an adjuvant therapeutic option for the treatment of pancreatic carcinoma.

Current British Society for Rheumatology guidelines state that there have been a number of malignancies, including lymphoma, reported
Correspondence: Dr Martin A. Lee, Flat 43, Mills Bakery, Royal William Yard, Plymouth, PL1 3GD, UK. Telefax: +44.7799.450793

E-mail:martinlee@doctors.org.uk

Key words: Anti-TNF alpha therapy, sarcoma, rheumatoid arthritis, etanercept, pleural.

Contributions: MAL, RB, MD, DS text writing.

Received for publication: 18 September 2011. Accepted for publication: 13 October 2011.

This work is licensed under a Creative Commons Attribution 3.0 License (by-nc 3.0).

(C) Copyright M.A. Lee et al., 2011

Licensee PAGEPress, Italy

Rheumatology Reports 2011; 3:e13

doi:10.4081/rr.2011.e13

from studies and post-marketing surveillance in association with the anti-TNF therapies. ${ }^{6}$ However, they also state that there is no evidence currently for an increase in risk of solid tumours or lymphoproliferative disease with the anti-TNF therapies above that which would be expected in the RA population. (There is a slight increase in prevalence of reticuloendothelial tumours in patients with RA. ${ }^{7-9}$ ) A study by Brown et al. highlighted 18 cases of lymphoma reported with etanercept therapy and 8 cases reported with infliximab therapy. ${ }^{10}$ The approximation of lymphoma risk with etanercept and infliximab therapy was 19 and 6.6 per 100,000 respectively (no dose duration was calculated). This risk was not thought to be significantly increased when compared to the National Cancer Institute's (NCI) ageadjusted lymphoma incidence rate for the general population of 18.3/100,000.

There is less study data surrounding antiTNF therapy and solid tumours than there is with lymphoma. Data from various studies has

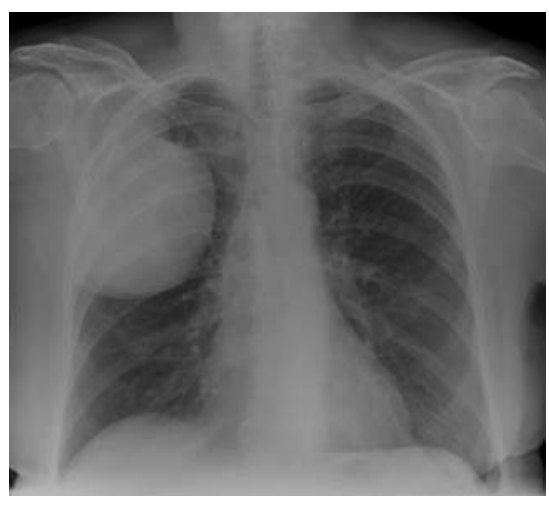

Figure 1. Chest radiograph showing large right upper zone mass. 
not demonstrated any significant increased risk of development of solid tumours in patients with RA treated with anti-TNF therapy over the general population. ${ }^{11-13}$ However, a placebo-controlled trial of etanercept plus cyclophosphamide for Wegener's Granulomatosis demonstrated that this combination of TNF inhibition and cyclophosphamide may increase the risk of cancer beyond that observed with cyclophosphamide alone. ${ }^{14}$ Six solid malignancies were observed during the trial and all occurred in the etanercept control group.

In summary, we have described the occurrence of an extremely rare tumour in a patient treated with anti-TNF $\alpha$ therapy for 7 years. Current data suggests that there is limited evidence for an increase in risk of solid tumours or lymphoproliferative disease in patients receiving anti-TNF $\alpha$ therapy. However, our experience of anti-TNF $\alpha$ therapy is still in its relative infancy. Therefore, as the number of patients on anti-TNF $\alpha$ therapy increases, and as patients remain on anti-TNF $\alpha$ therapy for longer, physicians should remain vigilant to the possibility of patients presenting with rare malignancies or indeed patients presenting with unusual presentations of more common malignancies. Any long-term complications of biologic therapies may only become apparent with time.

\section{References}

1. Nair B, Raval G, Mehta P. TNF- $\alpha$ inhibitor etanercept and hematologic malignancies: Report of a case and review of the literature. Am J Hematol 2007;82:1022-4.

2. Yan L, Anderson GM, DeWitte M, Nakada MT. Therapeutic potential of cytokine and chemokine antagonists in cancer therapy. Euro J Cancer 2006;42:793-802.

3. Anderson GM, Nakada MT, DeWitte M. Tumour necrosis factor- $\alpha$ in the pathogenesis and treatment of cancer. Curr Opin Pharm 2004;4:314-20.

4. Tsimberidou AM, Giles FJ. TNF-alpha targeted therapeutic approaches in patients with haematologic malignancies. Expert Rev Anticancer Ther 2002;2:277-86.

5. Egberts JH, Cloosters V, Noack A et al. AntiTumour Necrosis Factor Therapy Inhibits Pancreatic Tumor Growth and Metastasis. Cancer Res 2008;68:1443-50.

6. Ledingham J, Deighton C. Update on the British Society for Rheumatology guidelines for prescribing TNF $\alpha$ blockers in adults with rheumatoid arthritis (update of previous guidelines of April 2001). Rheumatology 2005;44:157-63.

7. Prior P, Symmons DP, Hawkins CF, Scott DL, Brown R. Cancer morbidity in rheumatoid arthritis. Ann Rheum Dis 1984;43:128-31.

8. Baecklund E, Ekbom A, Sparén P, Feltelius N, Klareskog L. Disease activity and risk of lymphoma in patients with rheumatoid arthritis: nested case-control study. Br Med J 1998; 317:180-1.

9. Young A, Koduri G, Batley M et al. Mortality in rheumatoid arthritis. Increased in the early course of disease, in ischaemic heart disease and in pulmonary fibrosis. Rheumatology 2007;46:350-7.

10. Brown SL, Greene MH, Gershon SK et al. Tumour necrosis factor antagonist therapy and lymphoma development: twenty-six cases reported to the Food and Drug Administration. Arthritis Rheum 2002;46: 3151-8.

11. Askling J, Fored CM, Baecklund E et al. Haematopoietic malignancies in rheumatoid arthritis: lymphoma risk and characteristics after exposure to tumour necrosis factor antagonists. Ann Rheum Dis 2005;64:141420.

12. Askling J, Fored CM, Brandt L et al. Risks of solid cancers in patients with rheumatoid arthritis and after treatment with tumour necrosis factor antagonists. Ann Rheum Dis 2005;64:1421-6.

13. Geborek P, Bladström A, Turesson $\mathrm{C}$ et al. Tumour necrosis factor blockers do not increase overall tumour risk in patients with rheumatoid arthritis, but may be associated with an increased risk of lymphomas. Ann Rheum Dis 2005;64:699-703.

14. Stone JH, Holbrook JT, Marriott MA et al. Solid malignancies among patients in the Wegener's Granulomatosis Etanercept Trial. Arthritis Rheum 2006;54:1608-18. 